the sole or most prominent feature of an affective depressive disorder. Blumer has called this the pain prone disorder. ${ }^{3}$ Patients are usually rigid, hard working introverts who deny psychiatric problems. Associated features such as disturbance of sleep and lack of energy, or any sensation of pleasure, should be sought, for these support the diagnosis. Treatment with tricyclic antidepressants may be successful.

Causalgia, though tainted with a psychoneurosis in the past, is clearly organically mediated, though secondary depression is a common accompaniment. Weir Mitchell described the condition in soldiers in the American civil war. ${ }^{4}$ Causalgia is characterised by a burning pain, which is not confined to a specific dermatome, and with autonomic dysfunction as evidenced by oedema, abnormal sweating, and trophic changes. It may be the result of partial nerve injury or apparently minor injuries without lasting sequelae. The pain may not date from the neurological insult, and a delay of weeks or months is characteristic. Movement provokes the pain so that the affected limb is kept immobile and joints become stiff. The shoulder-hand syndrome is just one variety of this. Patients cannot bear to be touched, and clothing and bedclothes may trigger off excruciating pain. Causalgia is probably an example of pain arising from abnormal discharges from afferent nerve fibres, arising from a gradual alteration in the relation between different afferent pathways, and perhaps resulting in a central state of oversensitivity to denervation.

Sudeck described a further example of reflex sympathetic dystrophy. ${ }^{5}$ These cases occurred after minor trauma to the wrist or ankle joint. Early changes include spotty decalcification of the joint with hyperaemia and oedema; later atrophic changes are seen, and the limb becomes cyanotic, cold, and clammy. Pain may be severe and provoked by slight movement. Marsden et al (p 173) have described sustained muscle spasms and rhythmical myoclonic jerks associated with Sudeck's atrophy. The pathophysiology is again thought to be related to abnormal discharges from afferent fibres-this leads to interesting speculations about the genesis of other movement disorders. The history of movement disorders is littered with psychiatric explanations, but most neurologists now accept that disorders such as spasmodic torticollis, writer's cramp, and so on, have an organic basis. Similarly, we may have been slow in recognising that patients with post traumatic pain may have movement disorders. Painful legs and moving toes (which could be more simply called Spillane's syndrome, as he first described it) can come on after apparently minor nerve injury or arise spontaneously. ${ }^{6}$ Pain tends to be peripheral and is associated with bizarre writhing movements of the toes, although proprioception is normal. These cases appear to be separate from those described by Marsden and his colleagues, as the movements are sinuous and athetoid rather than myoclonic and the pain is less severe. Possibly, however, Spillane's and Marsden's syndromes form part of a spectrum with the same underlying pathogenesis, the initial event being damage to a peripheral nerve and subsequent secondary spinal cord and central elaboration.

What about the treatment of these disorders? All authors agree that early intervention is important. The psychiatric findings should be assessed early; are they primary or secondary, and does the pain suggest causalgia ? Physiotherapy started early may prevent the development of joint stiffness and dystrophy and hence speed return to work. An early return to work is an important prognostic factor in determining ultimate functional capacity. Causalgia is notoriously difficult to treat once it is established, and the sympathetic doctor must not become frustrated by the apparent futility of his treatment. Drugs such as carbamazepine are often tried, occasionally successfully, but analgesics are rarely effective for long term use. Not infrequently patients are referred for a more invasive form of treatment. Some patients will improve with most techniques, but no single procedure has a good enough success rate to recommend it to every patient. Local anaesthetic block will often take away pain for the duration of the block but surgical section at the same site may not work. There has been some success using guanethidine to block sympathetic outflow and this may be more related to a central action due to noradrenergic hypersensitivity. Deafferentation pain may respond to stimulation, be it at the level of the peripheral nerve, spinal cord, ventrocaudal thalamic, or internal capsule. About two fifths of patients will derive an excellent result from this procedure. ${ }^{7}$

Creating radiofrequency lesions central to the dorsal root is an alternative procedure which may be successful. Such procedures obviously require careful selection as to whether they are appropriate by a specialist in pain relief. Further definition of the role of endorphins and that of the substantia gelatinosa may lead to more selective means of controlling pain. Lest we forget, tricyclic antidepressants should always be tried in chronic pain, not only for their antidepressant properties but also for their possible analgesic effects.

Post traumatic pain is a difficult subject but it may be illuminated considerably by correct attention to the neurological findings and the psychiatric history. It should then become clear which patient may benefit from a predominantly determinist or psychiatric approach-many patients will require both.

C G Clough

Senior Neurological Registrar,

Midland Centre for Neurosurgery and Neurology,

Warley,

West Midlands B67 7JX

${ }^{1}$ Miller H. Accident neurosis. Br Med 7 1961; ; :919-25.

2 Symonds C Sir. Concussion and its sequelae. Lancet $1962 ; \mathrm{i}: 1-5$.

${ }^{3}$ Blumer D. The pain-prone disorder. In: Benson DF, Blumer D, eds. Psychiatric aspects of neurologic disease. Vol II. New York: Grune and Stratton Inc, 1982:179-94. (Seminars in Psychiatry Monograph.)

${ }^{4}$ Weir Mitchell S. Injuries of nerves and their consequences. New York: Dover Publications, 1977.

${ }^{5}$ Sudeck P. Uber die akute Entzündliche Knockenatrophie. Arch Klin Chir 1900;62:147-56.

${ }^{6}$ Spillane JD, Nathan PW, Kelly RE, Marsden CD. Painful legs and moving toes. Brain 1971;94:541-56.

7 Tasker RR, Organ LW, Hawrylyshyn P. In: Bonica U, ed. Pain. New York: Raven Press, 1980:305-29.

\section{Are public health education campaigns worth while?}

Communities are sometimes subjected to intensive health education activity through mass communication for limited periods. Campaigns such as these usually aim at improving or maintaining the health of the population by persuading people to adopt or avoid certain types of behaviour. The topic concerned may be general, such as dental disease, or apply to a particular subgroup, such as cervical cancer. It may be one of immediate public concern, such as the need to contain an outbreak of rabies, or less threatening, such as the risk of developing cardiovascular disease. The message may be communicated through the press, the broadcasting media, 
meetings, demonstrations, pamphlets, and so on and be delivered by doctors, nurses, and other health professionals.

A recent campaign in Southampton to reduce the delay in women presenting to doctors with symptoms in the breast was relatively unsuccessful and calls this approach into question. ${ }^{12}$ In the year after a month of saturating the public with information about the advantages of the early diagnosis of breast cancer there was some overall reduction in the delay between the woman noticing a lump in the breast and seeing her doctor, but this largely followed the secular trend seen over the previous two years. Moreover, the most appreciable reductions were seen among those groups of women who tended to present earlier originally.

Had the campaign been more successful in the short term, then what? Should it be repeated, and after what interval ? Could the effective communication components be identified, or would any other health authority wishing to adopt the measure have to use the entire package? The real cost of the campaign was about $£ 10000$ (though the health authority did not have to pay all of that since many fees were waived) plus the cost of nearly 300 hours of professional time. Should expenditure be incurred on such a campaign without balancing it in economic terms against the estimated consequences for the public services and the individual?

The outcome of the Southampton campaign tallies with the findings of the Health Education Council's review of 250 evaluation studies from 27 countries. $^{3}$ These have shown that individual instruction is the best form of education, followed by a group approach, with impersonal, generalised instruction the least effective in influencing knowledge, attitudes, or behaviour (except where the behaviour required is a single action, such as producing a clinic attendance, though the Southampton campaign failed even on that count). Much of the health education purveyed through the mass media is relevant to only a small proportion of those at whom it is aimed (the "aerosol" effect) and, as seen in Southampton, is often given most attention by those least in need of it.

We have to draw a distinction, however, between the effects of mass media communication and area wide campaigns. The mass media may reinforce existing beliefs or help to crystallise attitudes. Through repetition they may produce long term benefits by creating a climate of opinion or setting the agenda of health issues for public discussion. ${ }^{4}$ For example, they have kept the links between smoking and disease prominent for a decade or more, and gradually the proportion of the population that smokes is being reduced. Yet audience research after the BBC television series So You Want to Stop Smoking showed that heavier smokers were the least likely to have watched the series or, if they did, to attempt to stop or succeed in doing so. ${ }^{5}$ Moreover, while an estimated 38000 smokers gave up at least partly because of the series, it did not appear to affect long term motivation, since the proportions reverting to smoking were the same whether they had given up with or without the series.

The attraction of a campaign concentrated on one geographical area comes from the possibility of coordinating local effort to meet a problem of particular local concern. Probably the outstanding example is the comprehensive community programme for health promotion in North Karelia (population 180 000) in eastern Finland. This began in 1972 out of local concern over the community's high mortality rates for cardiovascular disease and aimed at reducing these rates by improving the detection of hypertension and its control, reducing levels of smoking, and promoting low fat, high vegetable diets. ${ }^{6}$ Strategies were applied systematically to coordinating the entire community effort, to achieving environmental change (for example, making more low fat food available in the shops) and other intermediate goals. In addition to the mass communication methods, prestigious and respected people were recruited to influence community leaders (acknowledged to be a potent way of persuading the led), and the goals of the project were deliberately associated with pride and provincial identity.

Five years later the North Karelians were shown to have reduced their cigarette consumption, and their serum cholesterol concentrations and blood pressures were also lower than those of their neighbours who had not been the targets of a specific campaign (though the whole country must have become better informed on the aetiology of heart disease). The numbers receiving disability pensions for cardiovascular disease had gone down relative to the neighbouring population, and calculations suggested that the state had saved in disability payments over four times the amount spent on intervention activities.

This project, too, has been criticised for its indiscriminate use of methods of communication, while some of its behavioural achievements were of dubious practical importance, though statistically significant-for example, a reduction in the average number of cigarettes smoked of one per smoker more than in the reference population. ${ }^{7}$ Nevertheless, a later report has claimed that the downward trend in mortality from coronary disease in North Karelia has been steeper than in both the neighbouring reference area and the rest of Finland. ${ }^{8}$

Effective preventive policies in the community probably depend (as much as anything) on potentially influential instructors such as doctors and public health nurses, identifying with the specific health goals. Their numerous one to one contacts over extended periods allow them selectively to inform and persuade those groups least capable of assimilating information from the mass media and those unable or unwilling to attend meetings or health promotion events. If such efforts are to be properly planned and evaluated the community must have an efficient system of health intelligence. It would need a commitment on the part of local leaders to set goals for the health of their communities and, above all, a system of coordinating the individual educational efforts.

The effectiveness of this form of low key, prolonged intervention on an area wide basis calls for early, critical appraisal.

B T WiLliams

Senior Lecturer in Community Medicine,

University of Sheffield Medical School,

Sheffield S10 2RX

'Christmas P, Nichols S. "Don't take a chance"-a public campaign to encourage the early reporting of breast symptoms. Health Education fournal $1982 ; 41: 61-8$.

${ }^{2}$ Waters WE, Nichols S, Wheeller MJ, Fraser JD, Hayes AJ. Evaluation of a health education campaign to reduce the delay in women presenting with breast symptoms. Community Med 1983;5:104-8.

${ }^{3}$ Gatherer A, Parfit J, Porter E, Vessey M. Is health education effective? London: Health Education Council, 1980.

${ }^{4}$ McCron R, Budd J. Mass communication and health education. In: Sutherland I, ed. Health education perspectives and choices. London: George Allen and Unwin Ltd, 1979:199-216.

${ }^{5}$ British Broadcasting Corporation. So you want to stop smoking-results of a follow-up one year later. London: BBC Broadcasting Research, 1983. (BBC Broadcasting Research Special Report 83/15.81/16.)

${ }^{6}$ World Health Organisation. Community control of cardiovascular diseases. The North Karelia project. Copenhagen: WHO Regional Office for Europe, 1981.

${ }^{7}$ Klos DM, Rosenstock IM. Some lessons from the North Karelia project. Am f Public Health 1982;72:53-4.

${ }^{8}$ Salonen JT, Puska P, Kotte TE, Tuomilehto J, Nissinen A. Decline in mortality from coronary heart disease in Finland from 1969 to 1979. $\operatorname{Br} M e d \mathcal{F} 1983 ; 286: 1857-60$. 